\title{
Silver as a capturing material for iodine released from lead-bismuth eutectic in various conditions
}

\author{
Erik Karlsson $^{1,2} \cdot$ Jörg Neuhausen ${ }^{1}$ (1) $\cdot$ Robert Eichler $^{1,2} \cdot$ Ivan I. Danilov $^{1,2} \cdot$ Alexander Vögele $^{1} \cdot$ Andreas Türler $^{2}$
}

Received: 4 February 2021 / Accepted: 4 March 2021 / Published online: 21 April 2021

(c) The Author(s) 2021

\begin{abstract}
The usage of silver as a filtering material for removal of iodine from the gas phase of a lead-bismuth eutectic based nuclear reactor was investigated in various atmospheres representing normal operation as well as accident conditions. Thermochromatography experiments were performed to quantify the retention experienced on a silver surface by iodine species evaporated from a lead-bismuth eutectic sample. Measured adsorption enthalpies ranged from -171 to $-208 \mathrm{~kJ} \mathrm{~mol}^{-1}$ with observed differences attributed to various surface effects rather than a change in iodine speciation. The postulated adsorption mechanism is chemisorption of iodine atoms on the silver surface. Metallic silver fulfills the desired criteria for a capturing material in water-free filtering systems to be used as an alternative to traditional alkaline scrubbers commonly used in LWR systems.
\end{abstract}

Keywords Iodine $\cdot$ Lead-bismuth eutectic $\cdot$ Thermochromatography $\cdot$ Silver $\cdot$ Adsorption $\cdot$ Capture

\section{Introduction}

The concept of partitioning and transmutation has been discussed as a solution to the nuclear waste problem worldwide. Currently existing nuclear reactors are mostly lightwater reactors (LWRs) which produce end of cycle waste, which needs to be stored on geological time scales. To help overcoming this problem by reducing nuclear fuel usage and waste storage time, new technologies need to be introduced, typically framed under the name Generation IV (GenIV) reactors [1]. The most valuable advantage of these new reactor technologies lies in their capability of burning or transmuting long-lived fission products as well as minor actinides. These components will be extracted out of LWR fuel and inserted as fuel in this new reactor type. The reactor design concerned in this work is the MYRRHA reactor concept, a lead-bismuth eutectic (LBE) cooled proton accelerator driven system (ADS). Accelerator driven reactors are capable of operating sub-critically at a neutron deficit in the core as extra neutrons are supplied by the accelerator

Jörg Neuhausen

joerg.neuhausen@psi.ch

1 Laboratory of Radiochemistry, Paul Scherrer Institut, Forschungsstrasse 111, 5232 Villigen, PSI, Switzerland

2 Department of Chemistry and Biochemistry, University of Bern, Freiestrasse 3, 3012 Bern, Switzerland through spallation [2]. These extra neutrons enable fuel containing minor actinides and fission products to be used while sustaining a nuclear chain reaction. The neutron spectrum of the reactor is fast to enable higher efficiency of transmutation and fission of minor actinides as well as the major component ${ }^{238} \mathrm{U}$ in the fuel. Using a fast neutron spectrum also requires choosing a particularly suitable coolant, as regular light water moderates the neutrons into thermal energies where they are less useful. Lead-bismuth eutectic (LBE, $55.5 / 44.5 \% \mathrm{Bi} / \mathrm{Pb}$ ) is the chosen coolant for MYRRHA. However, alternatives for GenIV reactors are sodium metal, molten salts or gases. This change of coolant introduces safety advantages such as a large $\Delta T$ between melting and boiling point making loss-of-coolant-accidents (LOCAs) very unlikely. However, for the new safety assessments the evaporation and transport behavior of various fission products dissolved in the LBE must be systematically studied to ensure proper retention either in the LBE-matrix or on surfaces inside the reactor vessel or containment. In the present work, we address the behavior of iodine released from LBE. With respect to the deposition and capture of iodine species evaporated from LBE, two adsorbent surfaces have been studied in different gas atmospheres, fused silica as an analogue for concrete [3] and 316L stainless steel [4] as a major structural component suggested for the reactor. Both of these surface materials displayed only moderate retention, especially in an oxygen atmosphere where iodine may form 
particularly volatile species. Therefore, filtering solutions to control the transport of iodine inside the system in accident conditions are desirable.

In an LWR the iodine release is mainly addressed using scrubber technology, absorbing it in alkaline solutions [5]. Existing systems for doing this include venturi scrubbers, which are connected to the containment via a pipe with a burst disk to isolate the inside of the containment from the outside during normal operation [6]. In the event of an accident, the pressure inside the containment rises until the disk bursts and the gases from the containment go through the scrubbers that contain an aqueous solution of chemicals, which filter out volatile fission products such as iodine. For reactors that do not utilize water as a coolant and require a water-free environment for optimal operation, removal of iodine from the gas plenum of the containment using these systems is not ideal and alternatives must be considered.

Criteria that need to be fulfilled include retention of iodine in all possibly occurring chemical conditions as well as chemical compatibility with other chemical components in the system. For other radionuclides such as the activation product polonium, a simple stainless steel mesh has been suggested to be a sufficient capture device during normal operation conditions [7]. The problems appear in accident conditions where for example polonium has been shown to produce volatile species in the presence of moisture or oxygen [8-10]. To be a fully viable alternative to retain volatile iodine the filtering method needs to function in all conditions that are likely to be encountered in normal operation and accident scenarios. These conditions include ingress of oxygen from the atmosphere, water from breaks in pipes and steam generators and hydrogen from reactions with the water and hot metals.

From limitations imposed by the coolant chemistry such as the formation of volatile polonium species in the presence of moisture or oxygen discussed above, filtering solutions involving water are not viable. This limits the choice mostly to solid-phase absorbers, for which several workable alternatives exist [11]. One alternative is an activated charcoal filter which does efficiently capture iodine species, however, if oxygen is introduced to the system, the heat load of the radioactive iodine may cause the filter to ignite with subsequent spread of activity [12]. Zeolites are a group of inorganic silica-based porous materials which, when combined with well dispersed metals, are highly capable of filtering iodine from a gas stream. Particularly, silver-loaded zeolites have been proven very efficient $[13,14]$. These materials are highly versatile, providing good retention of iodine across a range of conditions as well as high thermal stability, which is desired [15]. The main mechanism of retention in such a filter is the chemisorption of iodine to Ag in the zeolite forming an Ag-I bond. To examine whether iodine evaporated from LBE experiences the same retention and whether such a material would be viable as a filter, a simplified system was constructed for experiments, consisting of a fused silica tube lined with silver foil.

The method deployed in this work is known as thermochromatography, which has a basis in quantifying the retention of a chemical species on a surface. This is done by evaporating the radionuclide into a gas stream of a certain composition. This gas stream may influence the initial chemical speciation of the radionuclide. Even several species can be formed. The gas stream carries these chemical species along the inside of a stationary tube, which is inserted into a special furnace, with a negative temperature gradient applied. The formed chemical components are separated laterally by their different adsorption retention on the surface of the stationary tube in the gradient. From measuring the lateral deposition distributions for long-lived isotopes along the tube as a function of experimental parameters such as, e.g., duration of the experiment, gas flow, gas composition or surface material, the formation of different chemical species as well as their retention properties on various stationary surfaces are assessed. Monte Carlo simulations are applied to extract thermodynamic quantities such as the adsorption enthalpy for the observed species [16].

\section{Experimental}

\section{Sample preparation}

Each sample consisted of lead-bismuth eutectic (SIDECH 99.999\%) mixed with 2 mass\% of elemental tellurium (Sigma Aldrich, Batch: MKBW7373V, 99.999\%) with each sample weighing approximately $20-50 \mathrm{mg}$. The samples were prepared in 2-g batches according to the methodology described in [17] with the dissolved oxygen level in the LBE reduced by heating it in presence of tantalum foil (Sigma-Aldrich, purity 99.9\%, $0.05 \mathrm{~mm}$ thickness) under vacuum. The batches were irradiated for $3 \mathrm{~h}$ in the SINQ neutron source with a thermal flux of $10^{13} \mathrm{n} \mathrm{cm}^{-2} \mathrm{~s}^{-1}$. The irradiation induces neutron capture in ${ }^{130} \mathrm{Te}$ to form ${ }^{131} \mathrm{Te}$, which subsequently decays via $\beta$-emission with a half-life of about 25 min into ${ }^{131} \mathrm{I}$, which is our desired product [18]. This method of sample production provides a good homogeneous distribution of iodine in the sample without introducing any iodine carrier.

\section{Thermochromatography}

In this work, two different gradient tube furnaces were used to evaluate silver as a capturing surface for iodine evaporated from LBE. One was used for dry experiments and a second one for operation with water-saturated (moist) carrier gases. The dry carrier gas setup featured a gas loop to 
clean and monitor the gas composition prior to and during the experiment. This was achieved using a SICAPENT® moisture absorber in the gas loop as well as a dew point meter (Michell Easidew EA2-TX-100), respectively. In experiments with dry inert carrier gases, a tantalum oxygen getter (heated to $1000^{\circ} \mathrm{C}$ ) was also used to lower the oxygen and water content of the gas in the loop. For this system a starting furnace adjacent to the gradient furnace (Fig. 1a) operated at $700{ }^{\circ} \mathrm{C}$ was used to initiate the evaporation of the sample. For moist carrier gases, no gas loop was used but rather a once-through system featuring a water bubbler. The carrier gas passes through this bubbler prior to the gradient furnace and is saturated with water. In moist conditions, the experiment was initiated by introducing the sample into the hot zone of the furnace with a pushing pin (Fig. 1b).

The gradient furnace used in moist conditions was manufactured by HTM Reetz, while the furnace used in the dry experiments was homemade by coiling an $\mathrm{Al}_{2} \mathrm{O}_{3}$ tube (length $570 \mathrm{~mm}, \varnothing_{\mathrm{o}}=17 \mathrm{~mm}, \varnothing_{\mathrm{i}}=12 \mathrm{~mm}$ ) with Kanthal wire $(\varnothing=1 \mathrm{~mm})$ with logarithmically increasing winding distances to achieve an approximately linear temperature gradient. In this $\mathrm{Al}_{2} \mathrm{O}_{3}$ tube, an INCONEL ${ }^{\circledR} 600$ tube (length $1150 \mathrm{~mm}, \varnothing_{\mathrm{o}}=10 \mathrm{~mm}, \varnothing_{\mathrm{i}}=8 \mathrm{~mm}$ ) was inserted. Finally, the thermochromatography column was introduced into the INCONEL $®$ tube and the latter was connected to the gas loop via Swagelok ${ }^{\circledR}$ connections. The temperature gradients established for both furnaces at various conditions (with a maximum set temperature of $700{ }^{\circ} \mathrm{C}$ ) are shown in Figs. 2, 3,4 . These gradients were measured prior to the experiments with a lateral resolution of one centimeter by stepwise insertion of a K-type thermocouple. Carrier gases used to influence the chemical speciation were helium, hydrogen and oxygen (all Messer® 5.0), with flow rates between 25 and $45 \mathrm{~mL} \mathrm{m^{-1 }}$ depending on the gas. The flow rates were controlled using a mass flow controller (Brooks Instrument B.V, $5850 \mathrm{~S} / \mathrm{E})$ and verified with an analog mini-BUCK Calibrator M-5 from A.P. Buck Inc. The chromatography columns used consisted of fused silica with lengths of $105 \mathrm{~cm}$ (dry conditions) and $119 \mathrm{~cm}$ (moist conditions) with an inside diameter of $5 \mathrm{~mm}$. The inside surface of these columns was clad with silver foil (Goodfellow, $0.020 \pm 0.003 \mathrm{~mm}$, purity: 99.9\%). This cladding covered the hot part of the column starting from the sample position and continuing for $45 \mathrm{~cm}$ down the column. Quartz wool was placed on both sides of the silver foil to hold the foil in place during and after the experiment. Pilot experiments indicated that this coverage range is sufficient to quantitatively capture all the iodine. The sample was placed upstream from the silver foil in a stainless steel (SS316L) boat approximately $3 \mathrm{~mm}$ wide and $1.5 \mathrm{~cm}$ in length custom manufactured by Manser AG. To capture aerosol particles a piece of quartz wool was placed downstream of the sample. Charcoal filters were present at the exit of each column to capture eventually volatile species not adsorbed to the silver or the fused silica.

After the hot part of the furnace used in an experiment had reached the set temperature it was allowed an additional three hours to properly stabilize the temperature gradient throughout the column. Before an experiment in dry carrier

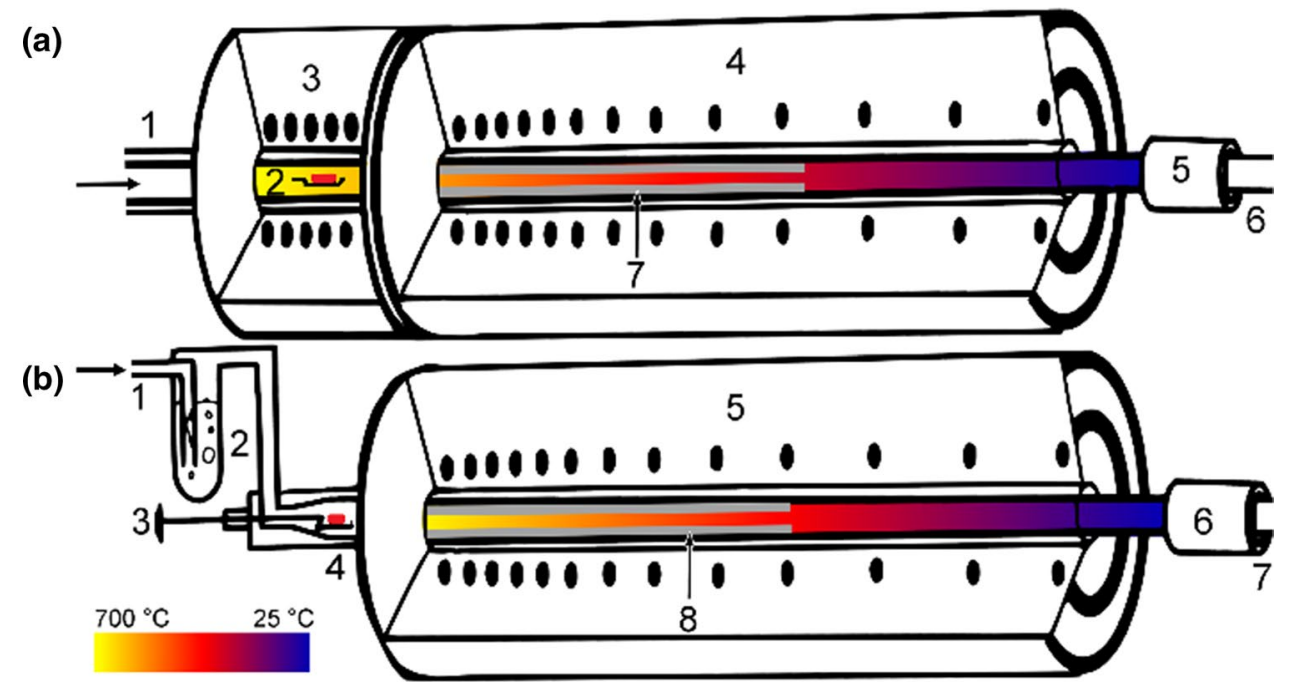

Fig. 1 Graphical representation of the experimental setups showing their individual parts. The color gradient in each furnace approximates the temperature gradient going from $700{ }^{\circ} \mathrm{C}$ to room temperature. Top a: Experimental setup for dry conditions: gas inlet (1), sample in sample boat (2), starter furnace (3), gradient furnace (4), charcoal filter (5), gas outlet (6), approximate position of silver lining of fused silica column (7). Bottom b: Experimental setup for water saturated conditions: gas inlet (1), bubbler for saturating gas with water (2), push pin to insert sample into hot zone (3), sample in sample boat (4), gradient furnace (5), charcoal filter (6), gas outlet (7), approximate position of silver lining of fused silica column (8) 
(a)

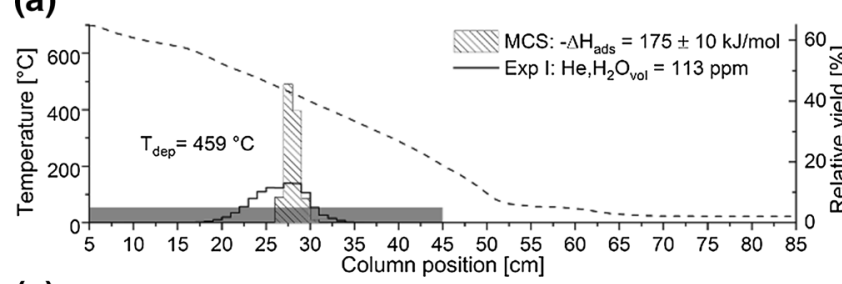

(c)

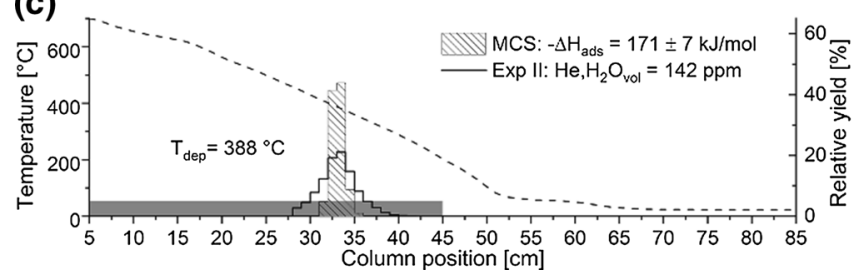

Fig. 2 Thermochromatograms of the measured depositions of iodine (black solid lines) in experiments with helium carrier gas on silver lined fused silica columns. Graphs a and $\mathbf{c}$ are experiments conducted in dry carrier gas while $\mathbf{b}$ and $\mathbf{d}$ are water saturated. The black dashed line displays the temperature gradient over the column with (b)

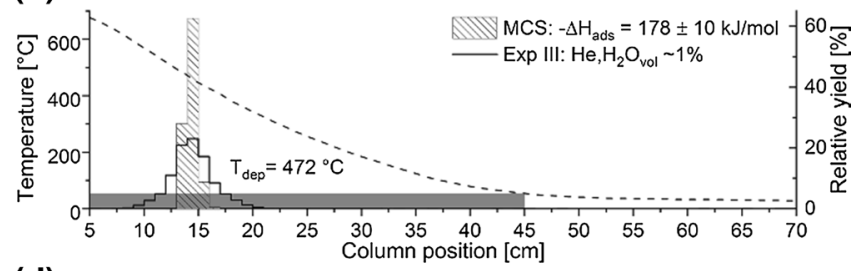

(d)

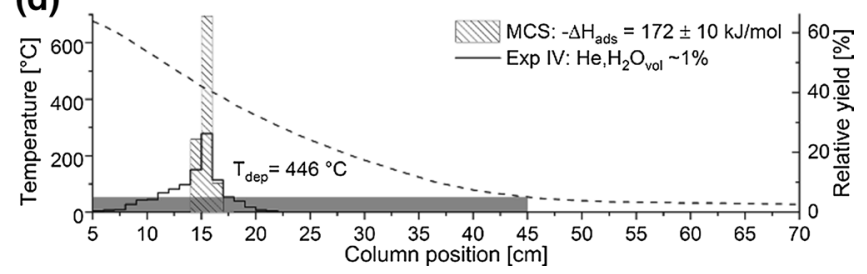

the hatched histogram showing the output of the Monte Carlo simulation for the displayed adsorption enthalpy $\Delta H_{a d s}$. Next to the deposition peak the temperature of the tube at the peak maximum is given. At the bottom of each figure, the position of the silver foil inside the fused silica column is shown in semitransparent grey shading (a)
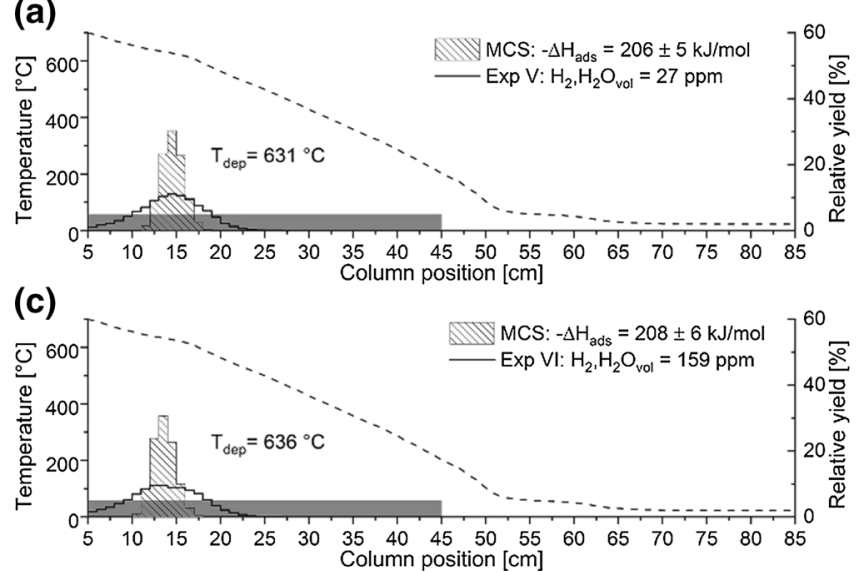

Fig. 3 Thermochromatograms of the measured depositions of iodine (black solid lines) in experiments with hydrogen carrier gas on silver lined fused silica columns. Graphs a and $\mathbf{c}$ are experiments conducted in dry carrier gas while $\mathbf{b}$ and $\mathbf{d}$ are water saturated. The black dashed line displays the temperature gradient over the column with

gas was started, the gas was allowed to circle through the system until the water content stabilized at a satisfactory level ( $<\sim 150$ vol. ppm). The experimental duration was either two or three hours depending on which furnace setup was used. In dry conditions the regime was as follows: One hour of evaporation, after which the starting furnace was turned off, followed by additional two hours of transport in the gas flow. For water saturated conditions the experiment ran for a total of two hours. (b)

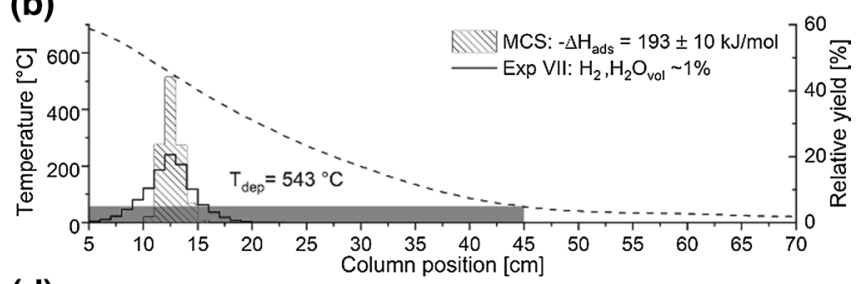

(d)

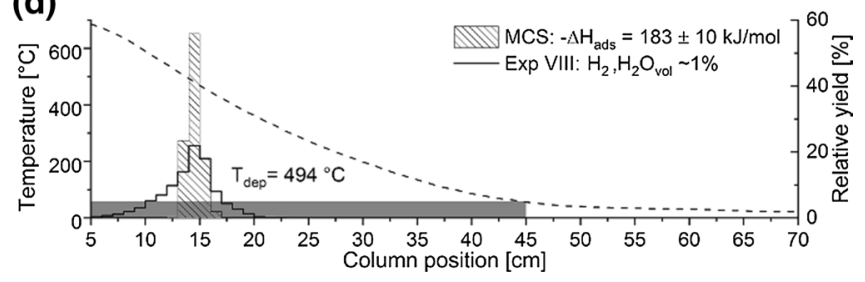

the hatched histogram showing the output of the Monte Carlo simulation for the displayed adsorption enthalpy $\Delta H_{a d s}$. Next to the deposition peak the temperature of the tube at the peak maximum is given. At the bottom of each figure, the position of the silver foil inside the fused silica column is shown in semitransparent grey shading

When the experimental time expired the furnaces were turned off, fixing the deposition pattern of the iodine inside the tube. To measure the pattern the column was marked up into $1 \mathrm{~cm}$ sections which were measured individually on an HPGe $\gamma$-detector using a lead collimator with a corresponding $1 \mathrm{~cm}$ opening. The data from the measuring of the column and the sample before and after the experiment was collected and analyzed using Canberra's Genie $2 \mathrm{k} \circledast$ package. Twelve experiments were performed in total. The corresponding experimental conditions such as carrier gas and its $\mathrm{H}_{2} \mathrm{O}$ content are listed in Table 1 . 


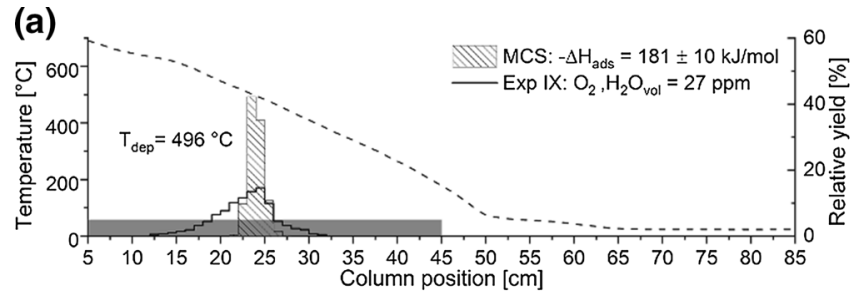

(c)

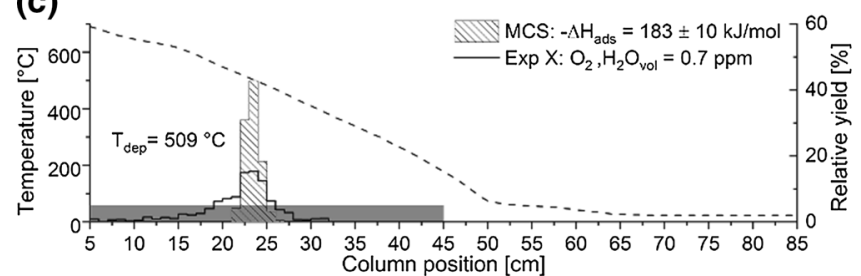

Fig. 4 Thermochromatograms of the measured depositions of iodine (black solid lines) in experiments with oxygen carrier gas on silver lined fused silica columns. Graphs a and $\mathbf{c}$ are experiments conducted in dry carrier gas while $\mathbf{b}$ and $\mathbf{d}$ are water saturated. The black dashed line displays the temperature gradient over the column with

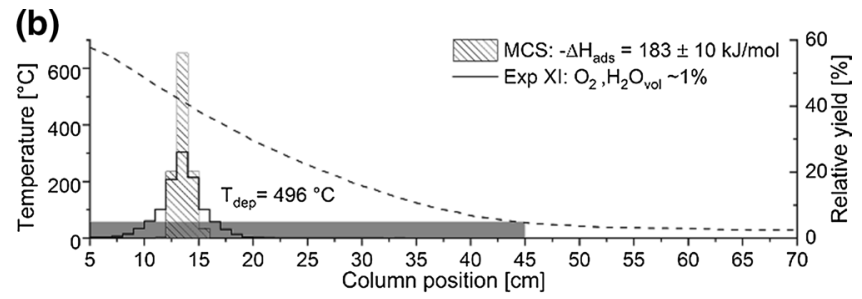

(d)

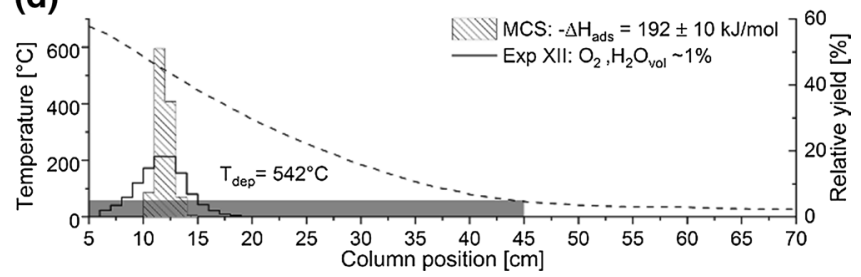

the hatched histogram showing the output of the Monte Carlo simulation for the displayed adsorption enthalpy $\Delta H_{a d s}$. Next to the deposition peak the temperature of the tube at the peak maximum is given. At the bottom of each figure, the position of the silver foil inside the fused silica column is shown in semitransparent grey shading

Table 1 List of experiments performed along with the respective carrier gases used, measured dew points and calculated water contents, deposition temperature $T_{d e p}$ of the ${ }^{131}$ I peak, the extracted adsorption enthalpy $\Delta H_{a d s}$ as well as the fraction of iodine evaporated from the LBE sample

\begin{tabular}{|c|c|c|c|c|c|c|}
\hline Exp No & Carrier gas & $\begin{array}{l}\mathrm{H}_{2} \mathrm{O} \text { content in gas } \\
\text { phase }(\mathrm{ppm})^{\mathrm{c}}\end{array}$ & Dew point $\left({ }^{\circ} \mathrm{C}\right)$ & $-\Delta H_{a d s}\left(\mathrm{~kJ} \mathrm{~mol}^{-1}\right)$ & $T_{d e p}{ }^{131} \mathrm{I}\left({ }^{\circ} \mathrm{C}\right)$ & $\begin{array}{l}\text { Evaporated } \\
\text { fraction of }{ }^{131} \mathrm{I} \\
(\%)\end{array}$ \\
\hline I & \multirow[t]{2}{*}{ Dry He } & 113 & -41 & $175 \pm 10$ & 459 & $\sim 100$ \\
\hline $\mathrm{II}^{\mathrm{a}}$ & & 142 & -39 & $171 \pm 7$ & $388^{\mathrm{a}}$ & $96-99$ \\
\hline III & \multirow[t]{2}{*}{ Moist He } & $\sim 10,000$ & - & $178 \pm 10$ & 472 & $96-98$ \\
\hline IV & & $\sim 10,000$ & - & $172 \pm 10$ & 446 & $\sim 100$ \\
\hline V & \multirow[t]{2}{*}{ Dry $\mathrm{H}_{2}$} & 27 & -53 & $206 \pm 5$ & 631 & $97-100$ \\
\hline VI & & 159 & -38 & $208 \pm 6$ & 636 & $94-96$ \\
\hline VII & \multirow[t]{2}{*}{ Moist $\mathrm{H}_{2}$} & $\sim 10,000$ & - & $193 \pm 10$ & 543 & $75-79^{\mathrm{b}}$ \\
\hline VIII & & $\sim 10,000$ & - & $183 \pm 10$ & 494 & 97-99 \\
\hline IX & \multirow[t]{2}{*}{ Dry $\mathrm{O}_{2}$} & 27 & -53 & $181 \pm 10$ & 496 & $22-25$ \\
\hline $\mathrm{X}$ & & 0.7 & -78 & $183 \pm 10$ & 509 & No data \\
\hline XI & \multirow[t]{2}{*}{ Moist $\mathrm{O}_{2}$} & $\sim 10,000$ & - & $183 \pm 10$ & 496 & 59-64 \\
\hline XII & & $\sim 10,000$ & - & $192 \pm 10$ & 542 & $64-66$ \\
\hline
\end{tabular}

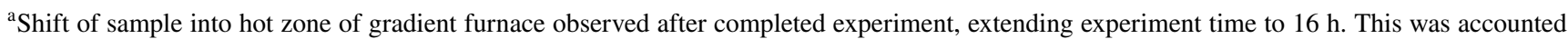
for in the Monte Carlo simulation

${ }^{\mathrm{b}}$ Sample found outside evaporation zone after experiment due to dislodging when maneuvering the sample pushing pin, leading to a reduced release fraction due to a lower evaporation temperature

${ }^{\mathrm{c}}$ Water content of carrier gas calculated using Michell Humidity Calculator v1.08 available at https://www.michell.com/uk/calculator

\section{Results and discussion}

The measured deposition temperatures and adsorption enthalpies extracted using Monte Carlo simulation are listed in Table 1 for the twelve experiments performed. Iodine evaporated from lead-bismuth shows a strong adsorption behavior at all conditions with satisfactory retention on the silver surface. The measured deposition temperatures range from $388{ }^{\circ} \mathrm{C}$ to $636{ }^{\circ} \mathrm{C}$ with extracted adsorption enthalpies of $-171 \mathrm{~kJ} \mathrm{~mol}^{-1}$ to $-208 \mathrm{~kJ}$ mo $1^{-1}$. This adsorption interaction is much stronger than the adsorption observed on reactor construction materials such as 316L stainless steel as well as on fused silica (concrete analogue) $[3,4]$. Oxidizing carrier gas was found to introduce a retention leading to incomplete evaporation of 
the iodine present in the LBE matrix. At inert and reducing conditions full or near full evaporation was achieved (Table 1).

An earlier study on the adsorption of iodine evaporated from LBE on fused silica surfaces employed thermodynamic calculations and empirically determined correlations between sublimation and adsorption enthalpies to assign a speciation to the evaporated and deposited iodine species [3]. The results of this work indicate the presence of the heavy metal iodide $\mathrm{BiI}$ in inert and reducing conditions, while oxidizing conditions induce the formation of monatomic iodine and more volatile iodine oxides and hydroxides. Based on considerations of bond energies [19], for an adsorbent/adsorbate combination such as silver and iodine it is likely that at high temperature the evaporated heavy metal iodide species experiences dissociation in favor of formation of iodine and bismuth both strongly bound to the silver surface. Additionally, formation of other compounds in the presence of oxidizing or reducing carrier gases is unlikely due to the strong interaction between iodine and silver and the thermal instability of compounds such as iodine oxides and hydroxides at the observed deposition temperatures. In an ab initio study on the chemisorption of halogens on the $\mathrm{Ag}(100)$ surface using an $\mathrm{Ag}_{5}$ cluster as a model, a binding energy of $-187 \mathrm{~kJ} \mathrm{~mol}^{-1}$ was calculated for an iodine atom bound to such a cluster [20]. This indicates that the adsorption enthalpies observed in all conditions throughout the present study are compatible with chemisorption of iodine atoms on a silver surface. Assuming this is the case, we end up with a situation where the iodine speciation is independent of the carrier gas.

The adsorption characteristics of iodine then still may be influenced by the carrier gas through surface effects induced by the gases, which may change the number of available $\mathrm{Ag}$ adsorption sites on the surface as well as their chemical state and their crystallographic characteristics. A study on morphological changes of silver surfaces under treatment with oxidizing, inert and reducing gases [21] indicates that indeed changes of the surface morphology may occur that can explain the variations in adsorption enthalpies observed in the present study.

\section{Helium carrier gas}

Inert gas conditions produce single peak depositions of iodine with adsorption enthalpies ranging from $-171 \mathrm{~kJ} \mathrm{~mol}^{-1}$ to $-178 \mathrm{~kJ} \mathrm{~mol}^{-1}$ with deposition temperatures between $388{ }^{\circ} \mathrm{C}$ and $472{ }^{\circ} \mathrm{C}$ as shown in Fig. 2 . For helium, no surface modifications from the carrier gas are possible except baking off adsorbed impurities and changing the characteristics of the silver surface, potentially by diffusion of oxygen between bulk and surface [21]. In water-saturated conditions, no modification to the adsorption behavior is observed suggesting if adsorption of water molecules or $\mathrm{OH}$ groups happens, it does not significantly influence the adsorption enthalpy. The peak in Exp I displays a high temperature shoulder, which may be interpreted as an additional species with slightly higher adsorption enthalpy. This could be either born out of a chemical reaction superimposing the adsorption/desorption process, known as a transport reaction [22] of a single species or the influence from some impurity present on the silver foil.

We would like to highlight Exp II as an example of what happens when the experiment (or accident transient) is allowed to progress for a longer period of time. This experiment saw dislodging of the sample into the gradient furnace hot section upon closing of the setup. This fact was not detected until the experiment ended and the setup was opened again. The additional experimental time of $14 \mathrm{~h}$ (overnight) led to a decrease in deposition temperature of roughly $70{ }^{\circ} \mathrm{C}$. The fact that this experiment yields an adsorption enthalpy value very similar to the shorter Exp I when the proper experiment duration is taken into account proves that the adsorption process occuring here is reversible, which is required for the evaluation using Monte-Carlo simulation to determine thermochemical data. Thus, the long-term behavior can be simulated easily using the Monte Carlo simulation. Such simulations show that the deposition temperature converges for long times $(>1000 \mathrm{~h})$ resulting in a main deposition peak at roughly $300{ }^{\circ} \mathrm{C}$, displaying sufficient retention even over much longer time-periods.

\section{Hydrogen carrier gas}

Switching to reducing atmosphere gave singular depositions with adsorption enthalpies between -206 and $-208 \mathrm{~kJ} \mathrm{~mol}^{-1}$ in dry carrier gas and -183 to $-193 \mathrm{~kJ} \mathrm{~mol}^{-1}$ in water saturated conditions (Fig. 3). The deposition temperatures ranged from 500 to $550{ }^{\circ} \mathrm{C}$ in water saturated conditions up to about $630^{\circ} \mathrm{C}$ in dry conditions. While the adsorption characteristics in reducing atmosphere are similar to the ones in inert atmosphere, we observe a systematic increase in the deposition temperatures and higher absolute adsorption enthalpies. The increase in deposition temperature can be attributed to the reducing potential of the carrier gas. The silver foil used in the experiments was not pretreated and thus most probably was oxidized when starting the experiment. Silver oxide is generally not stable at the elevated temperatures the iodine depositions occur at in the present experiments. Thermodynamic data [23] indicate that it decomposes into the elements at temperatures $>150{ }^{\circ} \mathrm{C}$ at 1 bar oxygen pressure. Therefore, an oxide layer would tend to decompose even in inert or oxidizing gas atmosphere. However, the decomposition of such an oxide layer initially present on the surface will not occur instantaneously. Due to the strong reduction potential of hydrogen, the in-situ reduction of the oxide layer 
will be more efficient in experiments with hydrogen carrier gas, exposing a larger number of metallic adsorption sites on the surface compared to experiments in helium, which in turn facilitates Ag-I bonding. This increase is not as strong in water saturated hydrogen, probably because of the lower reduction potential of the hydrogen/water mixture compared to pure hydrogen. The present moisture may also cause the formation of $\mathrm{OH}$ groups on the surface [24], particularly at lower temperatures.

Based on the strong adsorption of iodine to the silver surface observed in hydrogen gas we may generally consider hydrogen as a cleaning agent, which when combined with heat results in the surface with the highest number of available metallic adsorption sites [25]. Generally, adsorption in hydrogen atmosphere in many cases is stronger than what is found between the same species and metallic surface in dry helium even if the surface has been pre-treated in hydrogen $[26,27]$. This is likely caused by diffusion of oxygen or similar impurities from the bulk to the surface of the material in the helium experiments, making the repopulation of minor impurities present on the surface very fast. In the corresponding hydrogen experiments, the impurities may be reduced and removed from the surface.

One aspect that requires consideration in these experiments with regard to the surface is the deposition of evaporated lead and bismuth. The reason this needs to be considered when working with iodine on a silver surface and not on, for example, a fused silica surface is the potential for overlap between the depositions of lead and bismuth and the iodine deposition. In hydrogen carrier gas it is especially important to highlight this aspect as the LBE surface is continuously cleaned of oxides facilitating the evaporation of LBE. We conclude however that if such an effect is present, the surface coverage is low enough that the main contributor to the adsorption behavior of iodine is still the silver surface. If depositions of lead and bismuth on the surface proved to have a high affinity towards iodine then the same effect should have been observed in fused silica tubes. Thus, we conclude that the influence of co-evaporated lead and bismuth in this case is minimal.

\section{Oxygen carrier gas}

Oxidizing atmosphere is the only condition where the silver surface is in danger of being attacked and corroded. Such effects were observed at the low temperature end of the silver foil as a matte finish in experiments where the silver foil extended into the range where $\mathrm{Ag}_{2} \mathrm{O}$ is thermodynamically stable. The observed adsorption enthalpies for iodine of -181 to $-183 \mathrm{~kJ} \mathrm{~mol}^{-1}$ in dry conditions and -183 to $-192 \mathrm{~kJ} \mathrm{~mol}^{-1}$ in water saturated conditions (Fig. 4) occur at high enough temperatures $\left(\sim 500\right.$ to $\left.540{ }^{\circ} \mathrm{C}\right)$ to suggest that if such processes are occuring in the present experiments, they are not substantially influencing the adsorption behavior of iodine. As mentioned previously the formation of $\mathrm{Ag}_{2} \mathrm{O}$ on the surface occurs only below a certain temperature (about $150{ }^{\circ} \mathrm{C}$ at 1 bar oxygen pressure) where the surface is able to retain the oxygen [23]. Studies on the morphological changes induced on silver surfaces by treatment with oxygen gas indicate that indeed no stoichiometric oxide phase is formed at high temperatures [21], supporting the idea that iodine is chemisorbed to a silver surface throughout the present series of experiments. Finally, the stronger adsorption behavior of iodine on silver in dry hydrogen carrier gas compared to dry oxygen is consistent with previous observations in similar studies with a difference in deposition temperature of approximately $100{ }^{\circ} \mathrm{C}$ [28].

Previously, iodine dissolved in LBE has been observed to form particularly volatile reaction products when evaporated from LBE into oxygen [3, 4]. This effect was postulated to result from oxidation of the iodine prevailing in oxidation state -1 in the liquid metal solution or the bismuth monoiodide evaporated from it. This oxidation leads to the formation of monatomic iodine and iodine oxides or hydroxides. Monatomic iodine would tend to be strongly chemisorbed to a silver surface as discussed above. Overall, the results obtained in the present experiments performed in oxygen atmosphere are consistent with the assumption of chemisorption of atomic iodine on a silver surface that has not been severely oxidized. The results also indicate that both iodine oxides and the hydroxides that may potentially form in moist oxygen are unstable with respect to the adsorbed state of iodine at the conditions of the high temperature deposition. This shows that silver or silver coated materials are good candidates for developing filter systems for capturing even the most volatile iodine containing species evaporated from LBE if kept at elevated temperatures.

Finally, a tendency for retention of iodine in the LBE matrix in an oxygen atmosphere is apparent when comparing the fractions of iodine released from LBE in oxygen to those observed in helium and hydrogen (Table 1). In dry and moist inert and reducing gases the evaporated fraction ranges between $94-100 \%$, however in oxidizing conditions this is reduced to between $22-66 \%$. The detailed mechanism behind this effect remains to be explored, however plausible hypotheses include formation of oxide layers on the surface of the LBE hindering evaporation as well as facilitating the formation of non-volatile heavy metal oxy-iodides.

\section{Conclusions}

Silver was shown to be an efficient adsorbent for capturing iodine evaporated from lead-bismuth eutectic in dry and water saturated helium, hydrogen and oxygen carrier gases. This indicates that silver is a capable material suitable for 
filtering volatile iodine species from the cover gas of an LBE-cooled ADS under various chemical conditions. The mechanism behind the retention on the silver surface is likely based on chemisorption of iodine atoms. Under conditions where molecular iodine species are evaporated from LBE, these most likely decompose in favor of iodine atoms bound to the silver surface instead of adsorbing as a molecule. Adsorption enthalpies of iodine on silver measured ranged from $-171 \mathrm{~kJ} \mathrm{~mol}^{-1}$ in dry helium gas to $-208 \mathrm{~kJ} \mathrm{~mol}^{-1}$ in dry hydrogen gas. The differences between the adsorption behaviors in different carrier gases is likely due to surface effects resulting from interactions of the surface with the gas rather than any influence on the speciation of the evaporated species. Dry hydrogen is the carrier gas in which the strongest adsorption interaction was observed, likely because its reduction potential favors the exposure of metallic adsorption sites on the silver surface. This is also consistent with the slight reduction in iodine adsorption strength when moving to water saturated hydrogen, which has a lower reduction potential. This finding indicates that a pretreatment of oxidized silver surfaces with hydrogen should enhance the adsorption of iodine in real life filtering systems designed based on this technology. The formation of multiple very volatile species in oxygen carrier gas which was previously observed in similar adsorption studies employing fused silica and steel surfaces $[3,4]$ is not found here due to the high deposition temperature and instability of these molecules in comparison to the strong Ag-I bond. In addition, no formation of an oxide scale has been observed in the high temperature section of the silver surface due to the thermodynamic instability of $\mathrm{Ag}_{2} \mathrm{O}$ even in oxygen atmosphere. Therefore, deposition temperatures in oxygen gas remain high. From these observations, it is not expected that the presence of oxygen in the gas phase severely affects the adsorption of iodine released from LBE on silver as long as the temperature of the filtering system is kept high enough to prevent the formation of silver oxide. Thus, for the conditions we are concerned with, silver has performed satisfactory as a filtering material fully capturing iodine with a strong adsorption at all tested conditions. For future practical applications, more detailed studies covering important topics such as use of microporous silver doped adsorbents including their filter capacity, performance at lower or higher operating temperatures and their efficiency for capturing volatile organic iodine compounds are highly desirable.

Acknowledgements This work was funded by the European Comission within the project MYRTE under EURATOM HORIZON2020 Grant Agreement No. 662186.

Author contributions EK: Conceptualization, Methodology, Software, Validation, Formal analysis, Investigation, Writing-Original Draft, Visualization. JN: Conceptualization, Validation, Data Curation, Writing-Review \& Editing, Visualization, Supervision, Project administration, Funding acquisition. RE: Validation, Methodology, Software, Writing-Review \& Editing, Visualization. IID: Methodology, Resources. AV: Methodology, Resources. AT: Validation, Writing-Review \& Editing, Supervision.

Funding Open Access funding provided by Lib4RI - Library for the Research Institutes within the ETH Domain: Eawag, Empa, PSI \& WSL.

Open Access This article is licensed under a Creative Commons Attribution 4.0 International License, which permits use, sharing, adaptation, distribution and reproduction in any medium or format, as long as you give appropriate credit to the original author(s) and the source, provide a link to the Creative Commons licence, and indicate if changes were made. The images or other third party material in this article are included in the article's Creative Commons licence, unless indicated otherwise in a credit line to the material. If material is not included in the article's Creative Commons licence and your intended use is not permitted by statutory regulation or exceeds the permitted use, you will need to obtain permission directly from the copyright holder. To view a copy of this licence, visit http://creativecommons.org/licenses/by/4.0/.

\section{References}

1. OECD Nuclear Energy Agency, The Generation IV International Forum: Annual Report 2017.

2. Aït Abderrahim H, Baeten P, De Bruyn D, Heyse J, Schuurmans P, Wagemans J (2010) MYRRHA, a multipurpose hYbrid research reactor for high-end applications. Nucl Phys News 20:24-28. https://doi.org/10.1080/10506890903178913

3. Karlsson E, Neuhausen J, Eichler R, Aerts A, Danilov II, Vögele A, Türler A (2020) Thermochromatographic behavior of iodine in fused silica columns when evaporated from lead-bismuth eutectic. J Radioanal Nucl Chem 326:1249-1258. https://doi.org/10.1007/ s10967-020-07420-1

4. Karlsson E, Neuhausen J, Vögele A, Eichler R, Türler A (2017) Evaporation and adsorption behaviour of radiotracers released from irradiated tellurium doped LBE, Annual Report 2016 Laboratory of Radiochemistry. Paul Scherrer Institut, Villigen, Switzerland

5. Clément B, Canrel L, Ducros G, Funke F, Herranz L., Rydl A, Weber G, Wren C (2007) State of the art report on iodine chemistry, Report NEA/CSNI/R(2007)1

6. Gulhane NP, Landge AD, Shukla D, Kale SS (2015) Experimental study of iodine removal efficiency in self-priming venturi scrubber. Ann Nucl Energ 78:152-159. https://doi.org/10.1016/j.anuce ne.2014.12.008

7. Obara T, Yamazawa Y, Sasa T (2011) Polonium decontamination performance of stainless steel mesh filter for lead alloy-cooled reactors. Prog Nucl Energ 53:1056-1060. https://doi.org/10. 1016/j.pnucene.2011.05.012

8. Gonzalez Prieto B, Lim J, Rosseel K, Martens JA, Aerts A (2016) Polonium evaporation from liquid lead-bismuth eutectic with different oxygen content. J Radioanal Nucl Chem 309:579-605. https://doi.org/10.1007/s10967-015-4670-8

9. Buongiorno J, Larson C, Czerwinski KR (2003) Speciation of polonium released from molten lead bismuth. Radiochim Acta 91:153-158. https://doi.org/10.1524/ract.91.3.153.19984

10. Gonzalez Prieto B (2015) Evaporation of polonium from leadbismuth eutectic nuclear coolant, (Ph.D. Thesis), KU Leuven, Leuven, Belgium

11. Riley BJ, Vienna JD, Strachan DM, McCloy JS, Jerden JL Jr (2016) Materials and processes for the effective capture and 
immobilization of radioiodine: a review. J Nucl Mat 470:307-326. https://doi.org/10.1016/j.jnucmat.2015.11.038

12. Lorenz RA, Martin WJ, Nagao H (1973) Behavior of highly radioactive iodine on charcoal. In: Proceedings of the 13th AEC Air Cleaning Conference, CONF-740807-10, San Franscisco, USA

13. Matsuoka S, Nakamura H, Tamura T (1984) Stability and chemical form of iodine sorbed on silver-exchanged zeolite X. J Nucl Sci Tech 21:862-870. https://doi.org/10.1080/18811248.1984.97311 25

14. Chapman KW, Chupas PJ, Nenoff TM (2010) Radioactive iodine capture in silver-containing mordenites through nanoscale silver iodide formation. J Am Chem Soc 132:8897-8899. https://doi. org/10.1021/ja103110y

15. Sakurai T, Izumo M, Takahasi A, Komaki Y (1983) Application of zeolites to remove iodine from dissolver off-gas, (II) thermal stability of iodine adsorbed on 13X, 5A, and Silver-exchanged Zeolites. J Nucl Sci Tech 20:784-786. https://doi.org/10.3327/ jnst. 20.784

16. Zvara I (2008) The inorganic radiochemistry of heavy elements: methods for studying gaseous compounds. Springer, Berlin. https://doi.org/10.1007/978-1-4020-6602-3

17. Danilov II, Neuhausen J, Vögele A, Eichler R, Müller E, Türler A (2018) Evaporation of iodine and polonium from liquid leadbismuth eutecticum, Annual Report 2017. Laboratory for Radiochemistry, Paul Scherrer Institut, Villigen, Switzerland

18. Nucleonica GmbH (2019) Nuclide Datasheets, Nucleonica Nuclear Science Portal (www.nucleonica.com), Version 3.0.151.0001, Karlsruhe, Germany

19. Luo YR (2009) Bond Dissociation Energies, In CRC Handbook of Chemistry and Physics, CRC Press/Taylor and Francis, Boca Raton, Fl, United States

20. Illas F, Rubio J, Ricart JM, Garrido JA (1986) Vibrational frequencies of halogens adsorbed on $\mathrm{Ag}$ (100) based on ab initio cluster model calculations. J Electroanal Chem 200:47-53. https:// doi.org/10.1016/0022-0728(86)90044-6

21. Nagy AJ, Mestl G, Herein D, Weinberg G, Kitzelmann E, Schlögl R (1999) The correlation of subsurface oxygen diffusion with variations of silver morphology in the silver-oxygen system. J Catal 182:417-429. https://doi.org/10.1006/jcat.1998.2388

22. Schäfer H (1962) Chemische Transportreaktionen: der Transport anorganischer Stoffe über die Gasphase und seine Anwendungen. Wiley-VCH Verlag GmbH \& Co, KGaA, Weinheim, Germany

23. Barin I (1995) Thermochemical data of pure substances, 3rd edn. Wiley-VCH, Weinheim. https://doi.org/10.1002/9783527619825

24. Dokuchits EV, Khasin AV, Khassin AA (2011) Interaction of hydrogen and water with oxygen adsorbed on silver. Reac Kinet Mech Cat 103:261-266. https://doi.org/10.1007/ s11144-011-0319-y

25. Holden SJ, Rossington DR (1964) Hydrogen adsorption on silver, gold, and aluminum. Studies of parahydrogen conversion. J Phys Chem 68:1061-1067. https://doi.org/10.1021/j100787a015

26. Maugeri EA, Neuhausen J, Misiak R, Eichler R, Dressler R, Piguet D, Vögele A, Schumann D (2016) Adsorption of volatile polonium species on metals in various gas atmospheres: Part II-adsorption of volatile polonium on platinum, silver and palladium. Radiochim Acta 104:769-779. https://doi.org/10.1515/ ract-2016-2575

27. Soverna S, Dressler R, Düllmann ChE, Eichler B, Eichler R, Gäggeler HW, Haenssler F, Niklaus JP, Piguet D, Qin Z, Türler A, Yakushev AB (2009) Thermochromatographic studies of mercury and radon on transition metal surfaces. Radiochim Acta 93:1-8. https://doi.org/10.1524/ract.93.1.1.58298

28. Eichler B, Baltensperger U, Kalberer M, Gäggeler HW, Trautmann N, Eberhardt K, Nähler A, Mendel M (1996) Adsorption of carrier-free radioactive isotopes of iodine on solid surfaces, Paul Scherrer Institut anual report 1995. Annex IIIA: Solid state research at large facilities, INIS-MF-14888, Villigen, Switzerland

Publisher's Note Springer Nature remains neutral with regard to jurisdictional claims in published maps and institutional affiliations. 